\title{
PEMBERDAYAAN UMKM MELALUI PELATIHAN PENYUSUNAN LAPORAN KEUANGAN UNTUK UMKM DI DESA KANGKUNG, KECAMATAN MRANGGEN KABUPATEN DEMAK
}

\author{
Nurul Imani Kurniawati1 ${ }^{1}$, Stacia Reviany Mege $^{2}$, Riandhita Eri Werdani ${ }^{3}$, Maya Aresteria ${ }^{4}$, Kholidin $^{5}$ \\ Sekolah Vokasi Universitas Diponegoro \\ Email: niyanurulimani@gmail.com
}

\begin{abstract}
Small and Medium Enterprise (SME) also known as UMKM is growing rapidly and has become one of many sectors to support the Indonesian Economy. The lack of ability to make financial report has been a problem for UMKM inhibit them to gain loan or investment from financial institutions. The same problem also found at UMKM in Kangkung Village. The purpose of this community service is to train the entrepreneurs about preparing and making simple financial report. This community service is consist of four steps which started by pre survey then followed by UMKM survey, pre training and training activities. After participating in the training, the entrepreneurs have shown understanding about the importance of financial report, and have gained ability to prepare a standard financial report for their business. This community service is expected to be held continuously for the UMKM in Kangkung village
\end{abstract}

Keywords: Small and Medium Enterprises, UMKM, Financial Report 


\section{PENDAHULUAN}

Usaha Mikro, Kecil, dan Menengah (UMKM) berdiri di berbagai negara termasuk di Indonesia dan merupakan salah satu penopang perekonomian negara. UMKM yang berdaya adalah UMKM yang memiliki kemampuan permodalan yang cukup, memiliki akses yang luas baik terhadap investor, sumber bahan baku, calon konsumen dan para stakeholder lain, serta memiliki daya saing yang kuat. Untuk meningkatkan kemampuannya UMKM membutuhkan pelatihan, pendampingan, konsultasi dan temu usaha. Masalah atau hambatan yang seringkali dihadapi oleh UMKM tidak lari dari kurangnya kemampuan manajerial, keterampilan operasi, dan tentunya masalah permodalan (Anggraini dan Nasution, 2013). Hal ini juga menjadi perhatian pemerintah karena UMKM adalah sektor yang jumlahnya cukup banyak dan sangat potensial dalam menyerap tenaga kerja, selain itu memiliki peran penting dan berkontribusi besar untuk perekonomian negara (Wahyuni dkk, 2005).

Masalah permodalan pada UMKM tidak hanya mengenai kurangnya jumlah dana namun juga kurangnya sumber dana tersebut (Anggraini dan Nasution, 2013). Kendala yang menjadi penyebab UMKM sulit mengakses antara lain adalah tidak saling mengenal dengan sumber permodalan, masih kurang mengenal institusi keuangan formal seperti bank sehingga mereka sendiri diklasifikasikan belum bankable (Urata, 2000). Selain itu kurang akrabnya pengusaha UMKM dengan pembukuan, ataupun ketidakmampuan menyusun kelayakan usaha. Padahal pada dasarnya pemilik modal akan mempertimbangkan kelayakan usaha untuk membuat keputusan manajerialnya apakah akan memberikan modal kepada UMKM atau sebaliknya (Soegoto, 2014). Upaya-upaya yang dilakukan antara lain mempertemukan UMK dengan pemilik dana, memberikan pelatihan pembukuan dan penyusunan studi kelayakan usaha atau proposal pengajuan dana.

Untuk membantu pemilik usaha dalam melakukan pencatatan keuangan, sejumlah upaya mulai dari konvensional sampai modern seperti pembuatan dan pemanfaatan aplikasi akuntansi (accounting application) telah dilakukan untuk membantu kemudahan pembuatan laporan keuangan (Suhayati dan
Riandani, 2019). Namun penggunaan aplikasi modern akan tepat digunakan jika pelaku bisnis UMKM sudah mengerti dasardasar dari pelaporan keuangan, terlebih lagi, tidak semua pelaku bisnis UMKM mampu menggunakan teknologi tersebut.

Berbagai jenis UMKM juga berkembang di desa Kangkung, Kecamatan Mranggen, Kabupaten Demak, Jawa Tengah. Dengan luas wilayah sebesar 5,15 $\mathrm{km}^{2}$ desa Kangkung dihuni oleh 8.271 jiwa penduduk dengan presentasi hampir berimbang antara perempuan dan laki-laki. UMKM yang sudah berkembang di desa Kangkung masih relatif kecil dan dikelola secara tradisional karena merupakan usaha turun temurun dari generasi sebelumnya. Usaha yang dapat ditemukan seperti makanan, minuman, mebel, industri sangkar burung, tekstil, dan lainnya. Rendahnya pengetahuan di bidang tata kelola keuangan bisnis mengakibatkan rendahnya kapasitas produksi dan jangkauan pasar. Selain itu, pelaku bisnis UMKM di Desa Kangkung juga kurang memiliki keterampilan yang baik dalam pencatatan transaksi bisnisnya. Dari pemasalah di atas, maka disadari perlunya memberikan pelatihan penyusunan laporan keuangan untuk pelaku bisnis UMKM di Desa Kangkung.

\section{METODE PELAKSANAAN}

Kegiatan pengabdian kepada masyarakat ini dilakukan dalam beberapa tahapan yakni sebagai berikut. Tahapan yang pertama (1) adalah pra survey. Dilanjutkan dengan tahapan kedua (2) yakni survey UMKM, pengumpuan data potensi desa dan peran masyarakat. Tahapan yang ketiga (3) yakni pra kegiatan pendampingan dan pelatihan. Dan tahapan yang terakhir (4) adalah pelaksanaan pendampingan dan pelatihan.

Pada tahapan pertama yakni pra survey, tim pengabdian mengunjungi lokasi pengabdian, Desa Kangkung. Tujuan dari pra survey ini adalah untuk bertemu dengan aparat desa, menyampaikan kegiatan pengabdian dan mengajukan proposal kepada pihak desa untuk nantinya bisa dimediasi dengan pihak terkait.

Tahapan kedua, adalah survey UMKM. Setelah mengajukan proposal kepada aparatur Desa, tahap kedua ini adalah 
mengumpulkan data potensi Desa Kangkung, bertemu dengan beberapa UMKM untuk mengidentifikasi bisnis yang ditekuni, teknologi yang digunakan, bagaimana masalah permodalan, bagaimana pencatatan keuangan, dan informasi lainnya yang dibutuhkan.

Setelah memperoleh informasi tentang kondisi UMKM di Desa Kangkung, maka pengabdian masuk ke tahap yang ketiga yakni pra kegiatan pendampingan dan pelatihan. Tahapan kegiatan ini adalah mempersiapkan materi yang akan disampaikan kepada pelaku bisnis UMKM bersama dengan trainer dari Universitas Diponegoro, mempersiapkan mekanisme program pelatihan, serta memastikan kesiapan sarana dan prasarana untuk kegiatan pelatihan.

Tahapan terakhir ada pelaksanaan pelatihan dan pendampingan untuk pelaku bisnis UMKM di Desa Kangkung. Pelatihan dilakukan selama bulan ketiga hingga buan keempat dari seluruh tahapan pengabdian. Pelatihan dilakukan pada pukul 09.00 WIB s/d 12.00 WIB. Kegiatan pelatihan diikuti oleh peserta perwakilan UMKM Desa Kangkung. Pelatihan terdiri dari 4 sesi oleh trainer dan setiap peserta didampingi langsung oleh tim pengabdian Sekolah Vokasi Undip.

\section{HASIL DAN PEMBAHASAN}

Hasil dari setiap tahapan kegiatan dalam pengabdian kepada masyarakat ini mempengaruhi tahapan selanjutnya. Sehingga hasil dan pembahasan akan dijelaskan secara bertahap.

\section{Tahap 1 - Pra Survey}

Pada tahapan pertama ini, tim pengabdian bertemu dengan aparatur Desa Kangkung, mengajukan rencana kegiatan pengabdian yang akan dilaksanakan dan mendapatkan informasi awal tentang kondisi UMKM di desa tersebut. Pertemuan dilaksanakan di Kantor Desa Kangkung dan dihadiri oleh Tim Pengabdian yang terdiri dari lima orang Dosen Sekolah Vokasi Universitas Diponegoro dan dari pihak desa yakni Kepala Desa, Sekretaris Desa, dan beberapa orang perangkat desa.

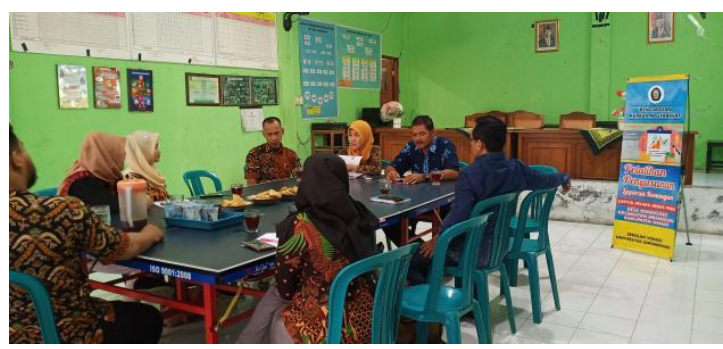

Gambar 1. Kegiatan Pra Survey

Hasil yang diperoleh dari kegiatan pra survey dapat dilihat pada tabel 1 .

\begin{tabular}{l|lr}
\hline Informasi & Keterangan \\
\hline UMKM Desa & UMKM di Desa \\
Kangkung & $\begin{array}{l}\text { Kangkung bada } \\
\text { umumnya bergerak di } \\
\text { bidang: }\end{array}$ \\
mebel, tekstil, industri \\
sangkar burung, \\
makanan dan minuman. \\
\hline Organisasi & $\begin{array}{l}\text { Terdapat organisasi } \\
\text { Masyarakat }\end{array}$ & $\begin{array}{l}\text { Karang Taruna yang } \\
\text { beranggotakan para } \\
\text { pemuda di Desa } \\
\text { Kangkung yang bisa } \\
\text { dimobilisasi untuk } \\
\text { mengikuti pelatihan }\end{array}$ \\
juga memotivasi para \\
pelaku usaha.
\end{tabular}

(Sumber: hasil olahan penulis, 2020)

\section{Tahap 2 - Survey UMKM}

Pada tahapan yang kedua, tim pengabdian mendapatkan informasi secara lebih mendetail tentang Desa Kangkung dan karakteristik penduduknya yang sudah disiapkan oleh apartur Desa. Data yang dikumpulkan dan diolah oleh tim pengabdian dapat dilihat pada tabel di bawah ini.

Tabel 2. Gambaran Umum Desa Kangkung

\begin{tabular}{|c|c|}
\hline Informasi & Keterangan \\
\hline Letak Geografis & $\begin{array}{l}\text { Kecamatan Mranggen } \\
\text { Kabupaten Demak, } \\
\text { Jawa Tengah }\end{array}$ \\
\hline $\begin{array}{l}\text { Luas Wilayah } \\
\text { Batas Wilayah }\end{array}$ & $\begin{array}{l}5,15 \mathrm{~km}^{2} \\
\text { Utara: D. Mranggen } \\
\text { Timur: D. Kalitengah } \\
\text { Selatan: D. Sumberejo } \\
\text { Barat: D. Batursari }\end{array}$ \\
\hline Demografis & penduduk \\
\hline
\end{tabular}




\begin{tabular}{|c|c|}
\hline Penduduk & $\begin{array}{l}8.271 \text { jiwa (Laki-laki } \\
4.140, \quad \text { Perempuan } \\
4.131) \\
\text { Agama yang dianut: } \\
\text { Islam- } 70 \% \\
\text { Kristen Protestan - } 11 \% \\
\text { Lainnya- } 17 \%\end{array}$ \\
\hline Fasilitas Desa & $\begin{array}{l}\text { Masjid, TK, SD, } \\
\text { SMP/MTs, SMA/MA, } \\
\text { Pertokoan }\end{array}$ \\
\hline $\begin{array}{l}\text { Mata } \\
\text { Pencaharian }\end{array}$ & $\begin{array}{l}\text { Wirausaha (UMKM), } \\
\text { petani, guru, karyawan } \\
\text { pabrik }\end{array}$ \\
\hline
\end{tabular}

(Sumber: hasil olahan penulis, 2020)

Selain mendapatkan gambaran umum mengenai Desa Kangkung, tim pengabdian juga mengumpulkan informasi mengenai UMKM dan permasalahan yang dihadapi. Rangkuman informasi mengenai UMKM dan permasalahannya dapat dilihat pada tabel 3 di bawah ini.

Tabel 3. Rangkuman Informasi UMKM

\begin{tabular}{l|l}
\hline Aspek Bisnis & $\begin{array}{l}\text { Permasalahan dari } \\
\text { UMKM }\end{array}$ \\
\hline Transaksi dgn & $\begin{array}{l}\text { 1. Ketergantungan } \\
\text { terhadap pemasok bahan } \\
\text { Supplier } \\
\text { Bahan Baku dari luar daerah } \\
\text { 2. Tidak ada pencatatatn } \\
\text { jelas terkait transaksi } \\
\text { keuangan dengan supplier } \\
\text { (langsung bercampur } \\
\text { dengan dana pribadi) }\end{array}$ \\
$\begin{array}{l}\text { 3. Kesulitan antuk } \\
\text { penyusunan aliran dana } \\
\text { penjualan }\end{array}$ \\
\hline $\begin{array}{l}\text { Transaksi } \\
\text { Pasar }\end{array}$ & $\begin{array}{l}\text { Belum bisa memenuhi } \\
\text { kebutuhan pasar }\end{array}$ \\
\hline $\begin{array}{l}\text { Proses } \\
\text { Keuangan }\end{array}$ & $\begin{array}{l}\text { Butuh waktu dan } \\
\text { beberapa tahap untuk } \\
\text { sekali transaksi }\end{array}$ \\
\hline $\begin{array}{l}\text { Ketersediaan } \\
\text { SDM untuk } \\
\text { pengelolaan } \\
\text { keuangan } \\
\text { beserta } \\
\text { pembuatan }\end{array}$ & $\begin{array}{l}\text { 1. Kekurangan tenaga } \\
\text { kerja lokal yang terampil } \\
\text { dalam penyusunan } \\
\text { laporannya }\end{array}$ \\
$\begin{array}{l}\text { laporan keuangan } \\
\text { 2. Tidak an adanya } \\
\text { pemisahan aliran dana } \\
\text { pribadi dengan dana } \\
\text { usaha, sehingga tidak } \\
\text { diketahui dengan pasti }\end{array}$ \\
\hline
\end{tabular}

\begin{tabular}{l|l}
\hline & $\begin{array}{l}\text { keuntungan atau kerugian } \\
\text { dari bisnis yang } \\
\text { dijalankan }\end{array}$ \\
\hline
\end{tabular}

(Sumber: hasil olahan penulis, 2020)

Dari hasil survey UMKM di tahap kedua ini, tim peneliti menyimpulkan perlunya pelatihan pada bidang keuangan untuk pelaku bisnis UMKM di Desa Kangkung, terlebih khusus mengenai pencatatan laporan keuangan.

\section{Tahap 3 - Pra Kegiatan Pendampingan dan} Pelatihan

Tahapan ini merupakan tahapan persiapan yang melibatkan tim pengabdian dari Sekolah Vokasi Universitas Diponegoro. Pada tahapan ini dirumuskan materi apa saja yang akan diberikan kepada peserta pelatihan dan bagaimana mekanisme pelatihan. Trainer atau narasumber yang dipilih untuk menyampaikan materi pelatihan adalah Dosen Akuntansi Sekolah Vokasi Universitas Diponegoro.

Program pelatihan keuangan yang telah dipersiapkan oleh tim pengabdian bersama narasumber adalah sebagai berikut.

\section{Tabel 4. Program Pelatihan}

\begin{tabular}{ll|lr}
\hline Sesi & & Kegiatan & \\
\hline Training & Sesi & Pengantar ran & Laporan \\
1 & & Keuangan Bisnis & \\
\hline Training & Sesi & Praktikum ran & dan \\
2 & & Pendampingan & \\
& & Penyusunan & Laoran \\
& & \multicolumn{3}{|l}{ Keuangan Bisnis } & \\
\hline
\end{tabular}

Training Sesi Diskusi antara trainer dan \begin{tabular}{l|l}
3 & peserta \\
\hline Training Sesi & Evaluasi
\end{tabular}

4

(Sumber: hasil olahan penulis, 2020)

Materi pelatihan dipersiapkan dalam bentuk print out dan juga PPT sehingga peserta dapat memperhatikan penjelasan trainer dan memiliki panduan yang dapat dibaca kembali. Materi pelatihan diambil dari Martono dan Harjito (2002) dan Warsono (2002), diolah dan dikemas secara menarik agar mudah dipahami. 
Tabel 5. Materi Pelatihan

\begin{tabular}{l|l}
\hline No & Materi \\
\hline 1 & $\begin{array}{l}\text { Penjelasan Umum Laporan } \\
\text { Keuangan }\end{array}$ \\
\hline 2 & $\begin{array}{l}\text { Laporan Laba Rugi Sederhana } \\
\text { (Income Statement) - Single step \& } \\
\text { Multiple Step }\end{array}$ \\
\hline 3 & $\begin{array}{l}\text { Laporan Perubahan Ekuitas/Modal } \\
\text { (Statement of Owner's Equity) }\end{array}$ \\
\hline 4 & \begin{tabular}{l} 
Laporan Neraca (Balance Sheet) \\
\hline 5
\end{tabular} \\
\hline \\
\hline
\end{tabular}

(Sumber: hasil olahan penulis, 2020)

Tahap 4 - Pelaksanaan Pelatihan dan pendampingan

Kegiatan pelatihan dan pendampingan dihadiri oleh perwakilan pelaku Bisnis UMKM Desa Kangkung, anggota Karang Taruna, aparatur desa, dan tim pengabdian Sekolah Vokasi UNDIP. Kegiatan pelatihan dibuka oleh Kepala Desa Kangkung, Bpk. Kamsari.

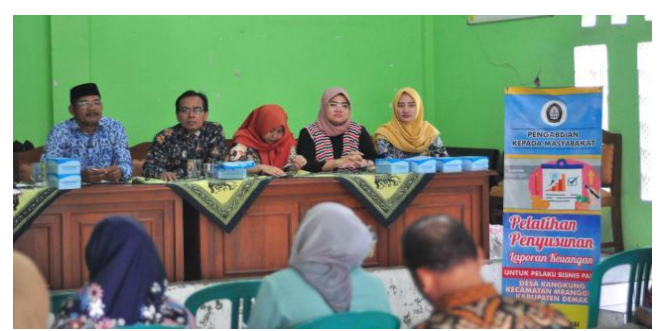

Gambar 2. Acara Pembukaan

Rincian kegiatan selama pelatihan dan pendampingan adalah sebagai berikut:

\section{Sesi 1}

Diisi oleh perwakilah dari Desa Kangkung yang memaparkan mengenai profil singkat Desa Kangkung, jenis UMKM yang ada serta berbagai macam kendala dan permasalahan yang dihadapi para pelaku UMKM khususnya pada industri mebel, sangkar burung, dan konveksi

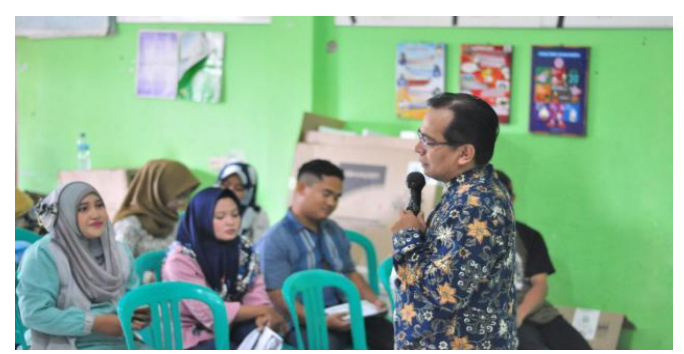

Gambar 3. Pelatihan

\section{Sesi 2}

Diisi oleh trainer, Ibu Maya Aresteria, S.E, M.Si, Akt, CA selaku narasumber pengabdian masyarakat dari pihak Sekolah Vokasi Universitas Diponegoro Semarang yang memaparan dan menjelaskan mengenai penyusunan laporan keuangan bagi para pelaku UMKM.

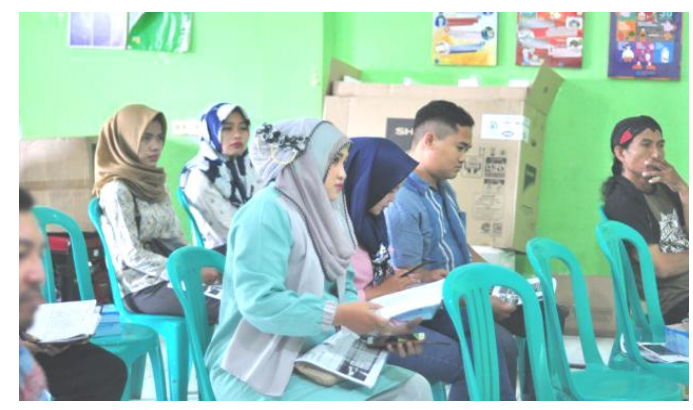

Gambar 4. Peserta Pelatihan

Program kegiatan Pengabdian kepada masyarakat dengan melakukan penyuluhan dan pelatihan bertujuan untuk membantu pelaku UMKM di Desa Kangkung untuk menggunakan dan menerapkan metode pencatatan keuangan sederhana agar mampu mendorong unit usaha menjadi layak pertanggungjawaban keuangan sehingga mendapat kepercayaan dari lembaga keuangan dan menjadi unit usaha yang layak kredit. Program ini dinilai berhasil saat pelaku UMKM bisa mengerti dan mempraktekan pencatatan keuangan usaha mereka. Dalam training sesi kedua (praktikum) para pelaku usaha dengan dipandu oleh trainer dan pendamping, dinilai sudah memahami dan mampu membuat laporan keuangan sesuai dengan keempat jenis laporan keuangan yang diminta. Pertanyaan dari peserta terkait teknis laporan keuangan sudah dijawab secara jelas dalam sesi tanya jawab oleh trainer.

\section{KESIMPULAN}

Kesimpulan yang dapat ditarik dari kegiatan Pengabdian kepada Masyarakat yang dilakukan Tim Sekolah Vokasi Universitas Diponegoro ini adalah:

1. Program Pengabdian kepada Masyarakat ini perlu dilanjutkan di tahun berikutnya secara berkesinambungan sehingga pengrajin atau pengusaha Kecil dan Menengah diberi pelatihan penyusunan 
laporan keuangan karena sebagian besar mereka masih kesulitan untuk mengoperasikan dan melakukan penyusunan laporan keuangan bagi usahanya.

2. Program pengabdian ini memberikan modul dalam penyusunan laporan keuangan sehingga dapat dimanfaatkan oleh pelaku UMKM.

3. Pelatihan ini menghasilkan kesepakatan antara lain: jika para pelaku UMKM di Desa Kangkung mengalami kesulitan dalam penyusunan laporan keuangan, tim Pengabdian Sekolah Vokasi UNDIP dapat membantu untuk konsultasi atau tutorial berkaitan dengan penyusunan laporan keuangan.

\section{REFERENSI}

Anggraini, D dan Nasution, S. H. (2013). Pernana Kredit Usaha Rakyat (KUR) Bagi Pengembangam UMKM di Kota Medan (Studi Kasus Bank BRI). Jurnal Ekonomi dan Keuangan Vol.1, No. 3.

Wahyuni, Eti, dkk. (2005). Lilitan Masalah Usaha Mikro, Kecil, Menengah (UMKM) \& Kontroversi Kebijakan. BITRA Indonesia, Medan.

Urata, S. (2000). Policy Recommendations: Outline of Tentative Policy Recommendation for SME Promotion in Indonesia. JICA, Jakarta.

Soegoto, E. S. (2014). Entrepreneurship Menjadi Pebisnis Ulung Edisi Revisi. Elex Media Computindo. 6, 212-45.

Suhayati, E dan Riandani I. (2019). Accounting Application for Small Medium Enterprises. IOP Conference Series: Materials Science and Engineering 662.

Martono dan Harjito. (2002) Manajemen Keuangan. Edisi Pertama. Ekonosia. Yogyakarta.

Warsono. (2002). Manajemen Keuangan Perusahaan. Edisi Kedua. UMM. 